\title{
Uma invenção helenística: a construção da ideia de judaísmo em oposição ao helenismo no livro de 2 Macabeus*
}

\author{
A Hellenistic invention: the construction of the idea of Judaism in \\ opposition to Hellenism in the book of '2 Maccabees'
}

Willibaldo Ruppenthal Neto**

Resumo: O presente artigo tem como proposta analisar a construção da identidade judaica no livro de 2 Macabeus a partir do uso do termo grego

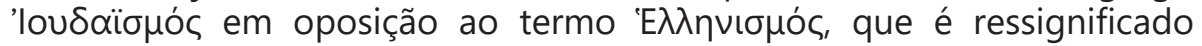
como o estilo de vida grego. Se intenciona analisar como a construção da ideia de "judaísmo", a partir da oposição à ideia de "helenismo", se assemelha à anterior construção da ideia de "bárbaro" e à posterior ideia de "cristianismo", ressaltando a importância da oposição como mecanismo de estabelecimento de identidades culturais na Antiguidade.

Abstract: This article aims to analyze the construction of the Jewish identity

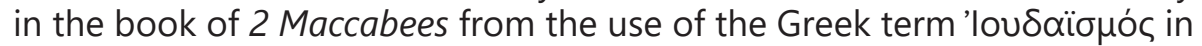

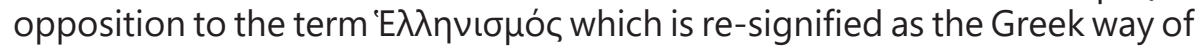
life. It is intended to analyze how the construction of the idea of "Judaism" from the opposition to the idea of "Hellenism" resembles the previous construction of the idea of "barbarian" and the later idea of "Christianity", emphasizing the importance of the opposition as a mechanism of cultural identities in Antiquity.

\author{
Palavras-chave: \\ Judaísmo; \\ Helenismo; \\ Período helenístico; \\ Identidade; \\ 2 Macabeus.
}

\section{Keywords:}

Judaism;

Hellenism; Hellenistic period;

Identity;

2 Maccabees.

\footnotetext{
*Este artigo é parte de minha dissertação de mestrado em História defendida na Universidade Federal do Paraná, em 2018, com modificações. Na ocasião, contamos com o apoio do CNPq.

** Doutorando em História pela Universidade Federal do Paraná (UFPR). Mestre e graduado em História pela mesma instituição e bacharel em Teologia pela Faculdade Batista do Paraná, onde atualmente é professor. É ainda membro do Núcleo de Estudos Mediterrânicos (Nemed), da UFPR.
} 


\section{Introdução}

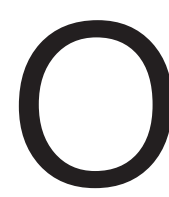

livro de 2 Macabeus é importante historicamente por inúmeras razões, ao ponto de Arnaldo Momigliano (1975b, p. 81) afirmar que se trata de "algo único na historiografia antiga". Uma destas razões está no fato de o livro de 2 Macabeus ser

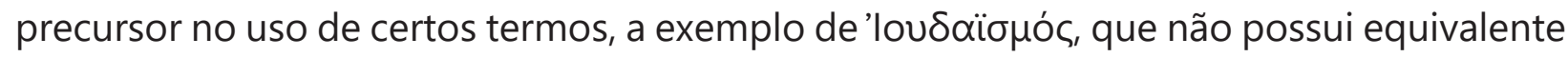
em hebraico, ${ }^{2}$ e do qual 2 Macabeus é a fonte mais antiga que se conhece.

Por tal caráter precursor, é possível se cogitar, inclusive, que o autor de 2 Macabeus (ou Jasão de Cirene, cuja obra tal autor busca resumir) tenha não somente

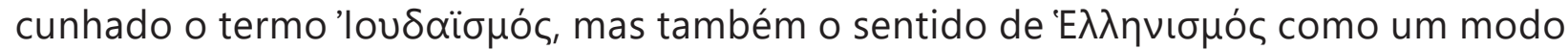

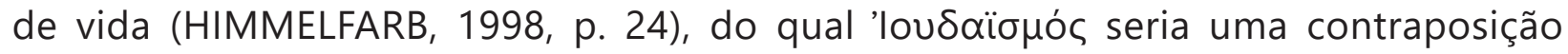
(HABICHT, 2006, p. 92). Ou seja, como bem indica Steve Mason (2007, p. 464),

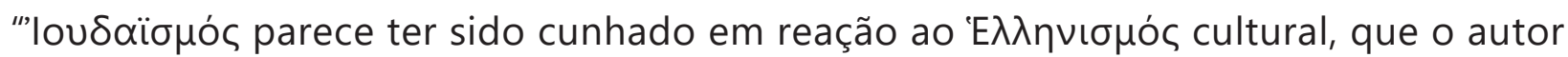
[de 2 Macabeus] também deve ter sido o primeiro a usar em sentido de 'helenização'". Porém, independentemente de ser uma criação de 2 Macabeus, cabe analisar as

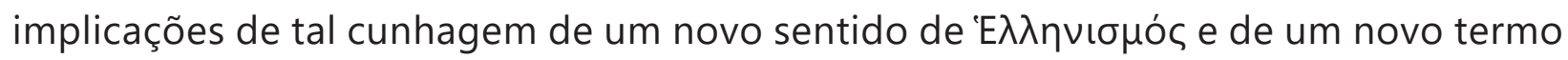

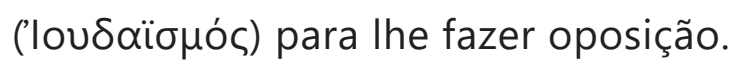

\section{Cultura, identidade e identidade cultural}

Para se compreender não somente a oposição estabelecida por 2 Macabeus entre helenismo e judaísmo, mas também seu significado histórico como construção identitária, é necessário se compreender o que é cultura, o que é identidade, e o que são identidades culturais.

Segundo Raymond Williams (1992, p. 13), a cultura pode ser compreendida de duas formas: em sentido antropológico e sociológico, como um "modo de vida global distinto, dentro do qual percebe-se, hoje, um 'sistema de significações'"; e em sentido mais especializado, como "atividades artísticas e intelectuais". Apesar de haver certa relação entre estas duas concepções, segue-se aqui a primeira ideia de cultura, ou seja, sua concepção em sentido antropológico e sociológico. Assim, entende-se cultura não somente como um "modo de vida", mas, mais propriamente, um modo de vida que tem

\footnotetext{
2 Segundo Steve Mason (2007, p. 460), "nenhuma palavra do antigo hebraico ou aramaico se aproxima do nosso

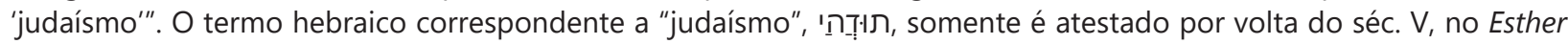
Rabbah (7, 11), aparecendo somente uma vez neste texto (MASON, 2007, p. 460, nota 9).
} 
relação com um grupo e uma sociedade, que fornece o "sistema de significações" dentro do qual se inserem os elementos que constituem uma cultura. ${ }^{3}$

As relações entre grupos e sociedades distintas, portanto, implicam relações culturais que podem ser percebidas a partir de uma perspectiva de interação ou contraposição, a qual resulta na reflexão a respeito dos "modos como a cultura se imbrica no processo de dominação e resistência" (KELLNER, 2001, p. 49). Nesta percepção, que muitas vezes se distancia e até mesmo esconde a fluidez e complexidade das relações culturais - que muitas vezes se dá por interações e negociações $-{ }_{1}^{4}$ se estabelecem ou até mesmo se criam pontos de diferenciação que buscam fundamentar e definir as culturas, os quais podem ser compreendidos como identidades culturais.

A identidade, como bem indicou Kathryn Woodward (2000), é necessariamente relacional, sendo especialmente marcada e até mesmo constituída pelas diferenças em relação a uma outra identidade. Se fundamenta, portanto, naquilo que cada pessoa entende como sendo seu diferencial social e cultural, diferenciando aquilo que compreende como "nós" em contraste com o que entende por "eles", ${ }^{5}$ especialmente quando se trata de uma identidade étnica, como no caso da identidade judaica. ${ }^{6}$ Tais diferenças, porém, são concebidas de forma auto referenciada, como lembra Tomaz Tadeu da Silva (2000, p. 74), de modo que dependem da identidade afirmada do mesmo modo que tal identidade depende das diferenças.

Sendo assim, as próprias diferenças são identitárias e, tratando-se de uma identidade de caráter cultural, pode-se dizer que tais diferenças são justamente as identidades culturais que definem uma cultura. As identidades culturais, portanto, são os pontos de distinção e especificação de determinada cultura em relação às demais, sendo tal distinção particularmente importante quando se busca enfatizar uma relação de

\footnotetext{
${ }^{3}$ A relação entre a cultura e o sistema de significações é tão profunda que se pode inclusive pensar a cultura como sendo "todas as atitudes ou aptidões apreendidas pelo homem enquanto membro de uma sociedade", como definiu Claude Lévi-Strauss (apud TODOROV, 2010, p. 38).

${ }^{4}$ André L. Chevitarese e Gabriele Cornelli (2003, p. 12) defendem a ideia de negociação entre culturas ao invés de imposição no contexto do mundo helenístico: "elas caracterizavam-se por sistemas abertos, estabelecendo negociações, admitindo trocas até um certo limite. Isto implica dizer que [...] não há espaço para noções de influências de uma cultura sobre a outra. Portanto, priorizar-se-á a ideia de negociação". Sendo assim, a oposição apresentada pelo livro de 2 Macabeus entre judaísmo e helenismo, assim como a ideia de "imposição" do helenismo sobre o judaísmo, são construções que obscurecem em grande medida o aspecto plural e relacional da realidade histórica.

${ }^{5}$ Uma vez que a identidade é uma realidade social, como lembra Norbert Elias (2005, p. 139), trata-se de uma percepção não do "eu" mas do "nós" em contraste com "eles": "O sentido que cada um tem de sua identidade está estreitamente relacionado com as relações de 'nós' e de 'eles' no nosso próprio grupo e com a nossa posição dentro dessas unidades que designamos 'nós' e 'eles'".

${ }^{6}$ Segundo Oliveira (1976, p. 5-6), "A identidade contrastiva parece se constituir na essência da identidade étnica [...]. Implica a afirmação do nós diante dos outros [...]. É uma identidade que surge por oposição. Ela não se afirma isoladamente. No caso da identidade étnica ela se afirma "negando" a outra identidade, 'etnocentricamente' por ela visualizada".
} 
oposição entre culturas, como de dominação e resistência, ${ }^{7}$ como é o caso do judaísmo e do helenismo tal como apresentados pelo livro de 2 Macabeus.

Segundo Stuart Hall (1996, p. 70), "as identidades culturais são pontos de identificação, os pontos instáveis de identificação ou sutura, feitos no interior dos discursos da cultura e da história". Ou seja, as identidades culturais são os elementos distintivos que são apresentados e, inclusive, muitas vezes construídos, através de discursos históricos específicos. Este é o caso da ideia de judaísmo constituída dentro do discurso de 2 Macabeus, que o fundamenta como uma identidade particular realizando o corte de especificação pela oposição à outra possibilidade cultural, o helenismo. Tal identidade cultural não somente estabelece uma oposição cultural, entre helenismo e judaísmo, mas também estabelece uma proposta de percepção específica da cultura judaica - dentre várias possíveis - como cultura de "resistência" ao helenismo supostamente imposto. ${ }^{8}$

\section{O judaísmo para além de 2 Macabeus}

Por meio do estudo a respeito da ideia de judaísmo em 2 Macabeus, se pode perceber o seguinte: do mesmo modo que a ideia de helenismo se desenvolve na Grécia Antiga a partir de sua relação com o conceito de bárbaro, a ideia de judaísmo se desenvolve em 2 Macabeus a partir de sua relação com o helenismo, que por sua vez também se reconfigura. Além de estar presente na obra estudada, porém, tal percepção identitária por parte dos judeus também se fará evidente na história posterior, transferindo-se da linguagem própria de um texto literário para uma concepção cultural que marcará a identidade de muitos judeus. ${ }^{9}$

A definição do judaísmo a partir da oposição ao helenismo, definindo-se como cultura de resistência, ${ }^{10}$ certamente se deu em um processo que ultrapassou não somente

\footnotetext{
${ }^{7}$ Como lembra Zygmunt Bauman (2005, p. 30), a identidade se constitui em situações nas quais um grupo perde suas "âncoras sociais", buscando uma definição estável do "nós" a fim de ter segurança. Neste mesmo sentido, segundo Alex Degan (2009, p. 218), "A identidade, então, é algo a ser inventado em momentos de crise, períodos em que a comunidade é atacada ou desiludida, se tornando insegura e irreconhecível".

${ }^{8}$ Não se propõe aqui definir o que é, de fato, a "identidade judaica". Afinal, como bem indicado por Bernardo Sorj (2008, p. 323), não "existe alguma definição de ser judeu que seja melhor que outra, superior ou inferior, capaz de se impor e excluir a outra". Ou seja, não se propõe apresentar o que seja a identidade judaica, mas analisar uma proposta específica de identidade judaica, que é aquela fornecida pelo livro de 2 Macabeus.

${ }^{9}$ É difícil de se medir a influência da própria obra literária neste processo. Afinal, um texto literário pode utilizar de uma narração histórica para influenciar a formação de aspectos identitários, como parece ser não somente o caso de 2 Macabeus, mas também de 3 Macabeus (JOHNSON, 2005).

${ }^{10}$ Tal aspecto da resistência como marca identitária pode ser percebido, por exemplo, na importância que a circuncisão ganha dentro do judaísmo, tornando-se não somente marca da diferença para com os outros povos, mas também um símbolo da resistência política contra a imposição política estrangeira, de modo que é inclusive apontada como uma das causas de importantes revoltas, a exemplo da Revolta dos Macabeus e da Revolta de Bar Kokhba. Sobre a circuncisão como símbolo de resistência, cf. Ruppenthal Neto e Frighetto (2018). Para além da circuncisão, o martírio é
} 
o domínio selêucida, mas também a Revolta dos Macabeus, do qual o livro de 2 Macabeus trata. Afinal, mesmo que o reinado de Antíoco Epifânio tenha sido marcante e permaneça simbólico na construção de uma identidade cultural, o helenismo não somente já havia estado presente desde antes de Alexandre como também estará presente durante o posterior domínio romano. Não foi à toa, portanto, que o caráter de resistência do judaísmo tenha tido um alvo tão preciso, que é a cultura grega, uma vez que foi a marca essencial do poder dominante não somente sob o Império Selêucida, mas também antes sob o Império Ptolomaico e depois sob o Império Romano, como lembra Tessa Rajak (2001, p. 3):

Qualquer que seja seu mérito, os judeus sabiam perfeitamente bem que a cultura grega daquele tempo era a cultura do poder dominante. Se deu, então, que para eles, esta cultura era um instrumento de três impérios sucessivos para os quais caíram, ${ }^{11}$ o Ptolomaico, o Selêucida e, finalmente, o Romano. Pois o domínio romano no Leste se deu em língua grega, incorporou ideias políticas gregas, e fomentou a literatura grega.

Mesmo que não fosse previsto pelo autor de 2 Macabeus, este aspecto helenístico do Império Romano se deu de forma proposital, uma vez que a própria fundação deste império como regime político e cultural, "em alguns aspectos, ${ }^{12}$ pretendia ser o herdeiro do império alexandrino e continuador de seu programa civilizador e conquistador, aceitando a helenização cultural para facilitar que o bárbaro quisesse se integrar às estruturas do Império Romano", como indica María José Hidalgo de la Vega (2005, p. 275-276). Com este intuito, Roma se tornou a "protetora do helenismo", como definiu a historiadora espanhola. ${ }^{13}$ Esta proteção ao helenismo, porém, se apresentou como uma ameaça a muitos judeus que, ao invés de serem atraídos à integração com o Império Romano, decidiram se rebelar contra o poder instituído. Afinal, o caráter do judaísmo como resistência não foi restrito ao livro de 2 Macabeus, que não somente incentivou mas também refletiu uma perspectiva em ascensão.

Na prática, portanto, a integração do Império Romano à cultura helenística tanto favoreceu a adesão por parte das elites greco-orientais ao sistema romano (HIDALGO DE

outro elemento no livro de 2 Macabeus que destaca a ideia de resistência, diferenciando-se de 1 Macabeus, no qual a ideia de resistência aparece, porém desvinculada do martírio (RUPPENTHAL NETO, 2019).

11 Segundo Morton Smith (1971, p. 75-76), o helenismo não foi somente marca destes impérios, mas também do Império Persa. A própria transformação do mundo helenístico, segundo este autor, aproximou a realidade oriental à antiga situação sob os persas mais do que em relação à Grécia Clássica, cf. Feldman, 1986, p. 109. Neste sentido, podese pensar em uma helenização da Judeia não somente anterior a Alexandre, mas também a partir do domínio persa.

${ }^{12}$ Não se deve exagerar nas relações entre o Império Romano e a cultura helenística, uma vez que não somente a identidade grega foi preservada, apesar da aculturação da cultura grega por parte dos romanos, da mesma forma que a "helenização" do Império Romano não chegou a implicar no abandono de sua moral e critérios culturais específicos por parte dos romanos (WOOLF, 1994, p. 135).

${ }^{13}$ Cf. Hidalgo de la Vega (2005, p. 281; 2006). 
LA VEGA, 2001, p. 156), como também a própria resistência por parte de seguimentos judaicos, cuja identidade já estava fundamentada na oposição do judaísmo ao helenismo. Deste modo, a cultura helenística deste Império Greco-Romano ${ }^{14}$ não somente teve como resultado a existência de uma elite partidária e submissa ao controle imperial, a exemplo de Flávio Josefo, ${ }^{15}$ mas também resultou nas diversas revoltas judaicas, estabelecidas sobre uma resistência ao helenismo e fundamentadas no exemplo fornecido pela Revolta dos Macabeus.

\section{A ideia de cristianismo em oposição ao judaísmo}

Outro indício posterior da confirmação da hipótese sugerida e exposta ao longo da pesquisa de oposição entre judaísmo e helenismo, é a continuidade desta corrente: se o primeiro elo é o conceito de bárbaro, que permite um novo elo, que é o conceito de helenismo, que por sua vez possibilita um elo seguinte, com o conceito de judaísmo, pode-se pensar no próprio conceito de cristianismo como o elo subsequente, estabelecido a partir da oposição ao judaísmo, e até mesmo ao helenismo. Ou seja, o estabelecimento

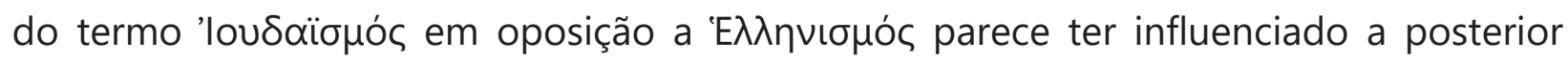

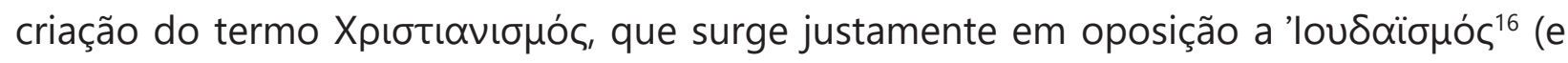

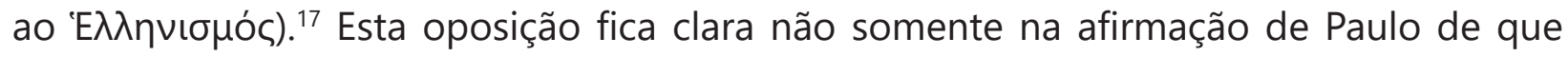

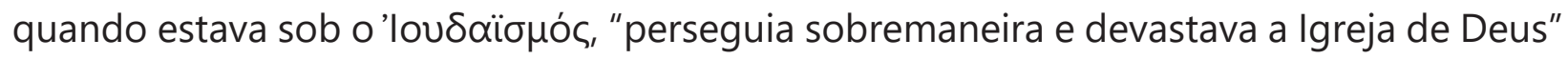

\footnotetext{
${ }^{14}$ Esta expressão, utilizada por Paul Veyne como título de um de seus livros, exprime a sua ideia de que "o Império Romano é a civilização helenística nas mãos brutais [...] de um aparelho de Estado de origem italiana" (VEYNE, 1993, p. 14). Segundo este autor, no caso do Império Romano, "a civilização, a cultura, a literatura, a arte e a própria religião provieram quase inteiramente dos gregos ao longo do meio milênio de aculturação" (VEYNE, 1993, p. 14).

${ }^{15} \mathrm{Cf}$. Flávio Josefo, Bellum Judaicum, 5, 367. A respeito da posição a favor dos romanos por parte de judeus, cf. Wilker (2012).

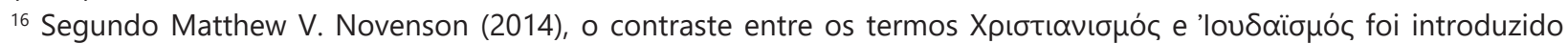
por Inácio de Antioquia, que possivelmente teria cunhado o termo grego Xpıбtıavıøuóc. Segundo Inácio, "é absurdo professar Jesus Cristo e se judaizar. Pois o Cristianismo não confiava no Judaísmo, mas o Judaísmo no Cristianismo, ao qual toda língua que crê em Deus se juntou" (Inácio de Antioquia, Epistula ad Magnesios, 10, 3). Cf. também Inácio

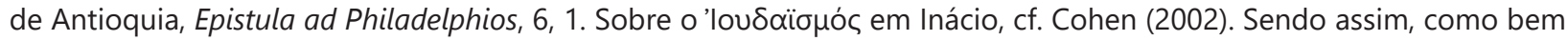

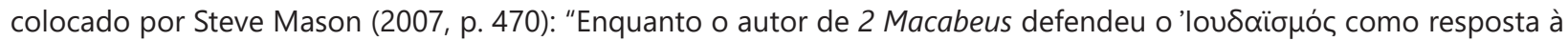

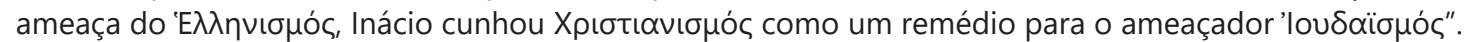

${ }_{17}$ Como bem indicado por Aaron Johnson (2006, p. 219), quando Eusébio pergunta como o Xpıбtıaviouós pode

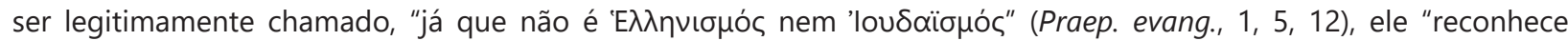
a necessidade de definir o Cristianismo por estes outros". De fato, em sua definição de Xpı

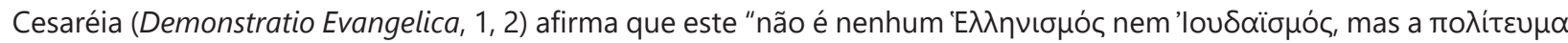

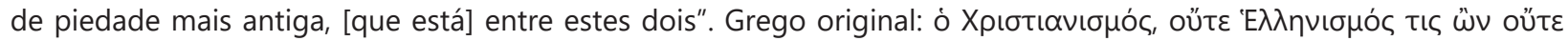

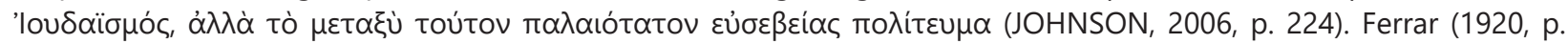
7) traduz como: "cristianismo não é uma forma de helenismo, nem de judaísmo, mas é uma religião com sua própria marca característica [characteristic stamp]".
} 
$(G l 1,13),{ }^{18}$ mas também na consideração de Tertuliano de que a partir de João Batista o Christianismus teria começado com o fim do Judaismus. ${ }^{19}$

Se na sua constituição formal o cristianismo se estabeleceu a partir de uma diferenciação para com o judaísmo, ${ }^{20}$ do qual procede, não era à toa que já havia se dividido desde o começo em grupos denominados "helenista" e "hebreu", como é dito em Atos 6, ${ }^{21}$ e que, posteriormente, como bem lembra Yehoshua Amir (1982, p. 39), veio a dividir o mundo todo em facções religiosas, denominadas cada qual sob um -ismo, tais

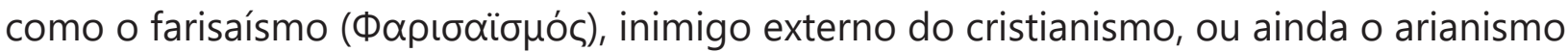

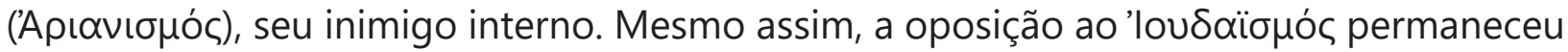
presente no cristianismo, de modo que ainda no séc. IV se falava dos cristãos "judaizantes" (SILVA, 2008).

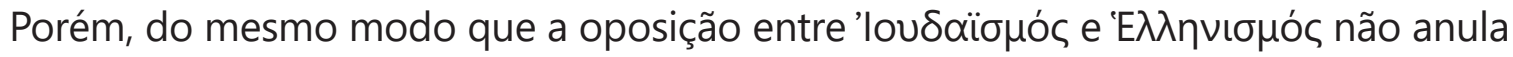

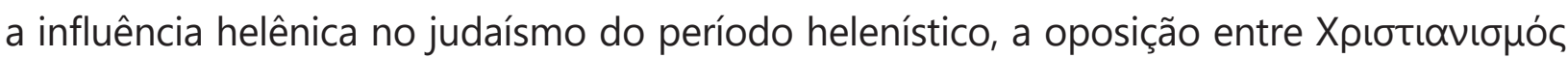

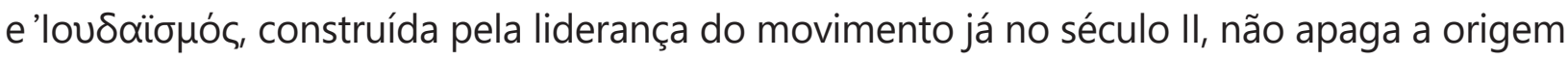
judaica do cristianismo, que surge como uma seita dentro do judaísmo, nem impede sua influência, uma vez que mesmo "os cristãos convertidos dentre os gentios não foram capazes de se desvencilhar por completo do patrimônio cultural judaico", como indicado por Gilvan Ventura da Silva (2008, p. 171). Em ambos os casos, trata-se de uma construção artificial, como sugerido como hipótese ao início da pesquisa e demonstrado ao longo dela.

\section{A oposição como uma construção}

Ao mesmo tempo que 2 Macabeus é a principal fonte da oposição entre judaísmo e helenismo, é também um dos maiores exemplos literários da influência da cultura helênica na

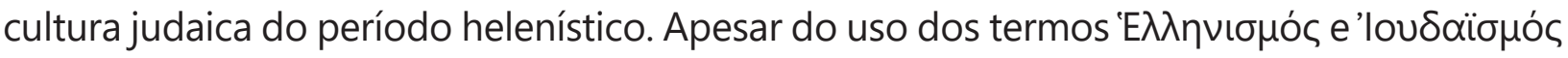
ter servido como metáfora para "a tensão entre razão e religião, entre racionalidade e espiritualidade, através das eras", como lembra Erich Gruen (2005, p. 264), de fato a questão

\footnotetext{
${ }^{18}$ Cabe, porém, se destacar que Paulo não utiliza o termo Xpı

${ }^{19}$ No original: "ad quem desinit Judaismus et a quo incipit Christianismus" (Tertuliano, Adversus Marcionem, 4, 338).

${ }^{20}$ Cf. Boyarin (2004).

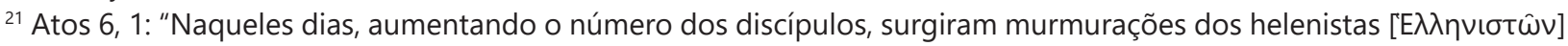
contra os hebreus ["Eßpáiouc]. Isto porque, diziam aqueles, suas viúvas eram esquecidas na distribuição diária". Como bem explica a BJ, os "helenistas" eram os judeus que, vivendo fora da Palestina, haviam adotado elementos de cultura grega, dispondo até mesmo de sinagogas particulares em Jerusalém, nas quais mesmo a Bíblia era lida em grego (Bíblia de Jerusalém [BJ], p. 1911, nota b). Segundo Werner Jaeger (2002, p. 18, nota 8), o termo "helenistas" era o termo oficial entre judeus e depois dentro do Cristianismo primitivo, para se referir às pessoas que "já não falavam o seu aramaico original na sua terra, ainda que o entendessem, mas grego, por eles ou as suas famílias terem vivido no estrangeiro em cidades helenizadas durante muito tempo, tendo regressado depois à sua pátria". Se trata, portanto, de uma denominação própria que indica uma divisão dentro do judaísmo que "foi transposta para o seio da Igreja Primitiva" (BJ, p. 1911, nota b).
} 
não é tão simples. Esta oposição, firme e absoluta, é evidentemente uma construção ideológica, bastante presente no livro de 2 Macabeus, mas cujo estudo do mesmo livro permite que seja evidenciada sua artificialidade. ${ }^{22}$ Afinal, o próprio livro, que se constrói

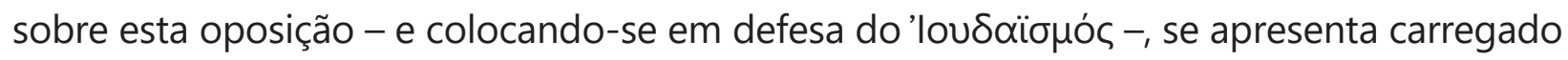
de elementos do "helenismo", não apenas em seus aspectos literários, mas também em toda a narrativa, tanto na estrutura de composição como no estilo, tanto nos acontecimentos narrados como na apresentação dos personagens. Mesmo a própria oposição entre

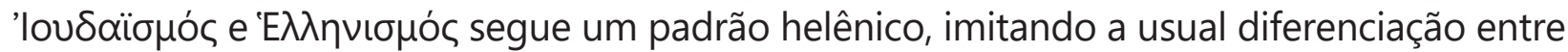
gregos e bárbaros. A realidade é muito mais complexa, sendo praticamente impossível de se determinar onde exatamente a obra é influenciada por elementos gregos ou judaicos. ${ }^{23}$ O livro de 2 Macabeus é, portanto, uma obra tipicamente helenística. ${ }^{24}$

Se faz evidente, portanto, que apesar de ser "fácil e tentador" interpretar os acontecimentos da Revolta dos Macabeus como "uma confrontação de judeu e grego, um embate de judaísmo e helenismo", ou ainda "a reafirmação das tradições da nação contra a aplicação coercitiva de uma cultura estrangeira" (GRUEN, 2005 p. 267), deve-se admitir, a partir do estudo aprofundado de 2 Macabeus e mesmo do contexto histórico, que a questão é muito mais complexa. Tal dicotomia, portanto, apesar de não somente estar presente como ainda ser um dos elementos centrais na mensagem de 2 Macabeus, é não somente artificial, mas também "enganadora e ilusória" (GRUEN, 2005, p. 267).

A Judeia, antes, durante e mesmo depois da Revolta dos Macabeus, certamente se viu sob profundas e intensas trocas culturais, de modo que passou por uma verdadeira "revolução cultural", como coloca Erich S. Gruen (2005, p. 267). ${ }^{25}$ A ideia de uma oposição absoluta entre

\footnotetext{
22 "Alguém pode concluir por este contraste entre os dois termos que o 'judaísmo' palestino e o 'helenismo' representam forças que são opostas em princípio; esta suposição é, claro, contrariada pelo fato de que o judeu Jasão [de Cirene]

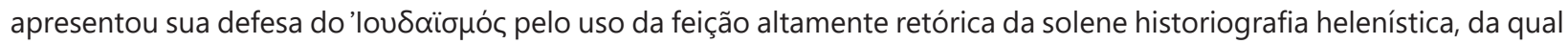
sua obra [2 Macabeus] é um dos exemplos mais bem conservados" (HENGEL, 1974, p. 2). Também John Collins (2005, p. 3) destaca o fato de que 2 Macabeus, o locus classicus da antítese entre judaísmo e helenismo, é um livro helenístico em vários sentidos.

${ }^{23}$ Se observarmos que "ninguém conseguiu até agora rigorosamente distinguir entre o que é hebraico e o que é grego em 1 Macabeus", como afirmou Arnaldo Momigliano (1976, p. 658), sendo uma obra que segue a tradição historiográfica bíblica e que foi escrita em hebraico (RUPPENTHAL NETO, 2017), se pode notar a dificuldade ainda maior do empreendimento no caso de 2 Macabeus, que é uma obra escrita em grego e a partir de elementos próprios da cultura grega, mas que pertence à cultura judaica e, portanto, possui influência da literatura e mesmo da língua hebraica.

${ }^{24}$ Assim como a historiografia é um gênero de influência grega, já que "o judeu culto era tradicionalmente um comentador de textos sagrados e não um historiador" (MOMIGLIANO, 2004, p. 49), também a historiografia nacional escrita em grego era um aspecto típico do período helenístico, uma vez que, como destaca Momigliano (2004, p. 46), "todas as nações que entraram em contato com os gregos na época helenística (e mesmo antes) produziram livros em grego a respeito de suas respectivas histórias nacionais". Exemplos neste sentido são a Babyloniaka, de Berossus e a Aegyptiaka, de Manetão, ou seja, as histórias nacionais da Babilônia e Egito, respectivamente, escritas em grego. Sobre a Babyloniaka, cf. Kuhrt (1987); sobre a Aegyptiaka, cf. Dillery (1999). Sobre ambas as obras, cf. Gmirkin (2006).

${ }^{25}$ Não se pode ignorar a influência transformadora do contato da Judeia com a cultura helenística, mesmo que venhamos a considerar tal influência como "um processo muito mais lento" que em outros casos, como afirmou Gideon Bohak (2000a, p. 351).
} 


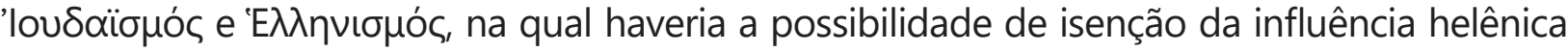
por parte da cultura judaica, não é somente artificial como também ingênua. ${ }^{26}$

Os judeus foram influenciados pelas culturas persa ${ }^{27}$ e helênica não somente por serem seus "dominadores", mas pelas relações que, efetivamente se realizavam. Assim como a Judeia "não era uma ilha fortificada" (GRUEN, 2005, p. 265), capaz de se defender das influências culturais do mundo helenístico ${ }^{28}$, também as próprias províncias selêucidas "não eram jardins murados" (KOSMIN, 2016, p. 49), mas antes espaços de relação cultural com troca de ideias e cosmovisões, seja pelas vias do comércio, como ainda por outros meios de relação.

Sendo assim, do mesmo modo que se faz necessário admitir-se a influência helenística na cultura judaica em seus mais variados grupos - incluindo até mesmo a comunidade de Qumran -, se faz necessário pensar-se também o inverso: a evidente influência judaica sobre o mundo helenístico. Afinal, independentemente da efetiva compreensão grega sobre a cultura judaica, ${ }^{29}$ houve não somente uma recorrente valorização desta "raça de filósofos", ${ }^{30}$ como ainda um impacto da religião judaica sobre o mundo greco-romano ${ }^{31}$, mesmo que em grande medida de modo negativo. ${ }^{32}$

\footnotetext{
${ }^{26}$ Concordamos, portanto, com Rachel Mairs (2013, p. 3123): "Qualquer noção de um conflito rígido [stark conflict] entre judaísmo e helenismo [...] deve ser rejeitada".

${ }^{27}$ Sobre as influências persas no judaísmo, cf. Soares (2009).

${ }^{28}$ Como bem lembra Lester Grabbe (2002, p. 59), a extensão da influência helenística chegou aos lugares mais remotos como Ai Khanum e a ilha de Failaka, no Golfo Pérsico, enquanto sua profundidade é percebida não somente em inscrições, mas também na arquitetura, literatura, etc, de modo que "nenhuma região pode escapar de alguma influência", permanecendo somente a questão de "em qual medida" esta influência se deu em cada região (COLLINS, 2005, p. 43).

${ }^{29}$ Gideon Bohak (2000b, p. 21) lembra que não se deve exagerar quanto à influência do monoteísmo judaico sobre o mundo greco-romano, afinal, mesmo que as categorias "monoteísmo" e "politeísmo" sejam importantes atualmente no estudo das religiões, é provável que o que nos parece óbvio como diferença não fosse evidente aos antigos. Mesmo que houvesse uma grande distância entre as concepções teológicas de gregos e judeus, tais diferenças não eram necessariamente compreendidas ou mesmo percebidas pelos gregos. Sobre a leitura greco-romana da religião judaica (FERNANDÉZ MARCOS, 1981).

${ }^{30}$ Esta ideia marcou presença no pensamento de Clarco, Megastenes e Teofrasto de modo que, segundo Martin Hengel (1974, p. 255), "os testemunhos gregos mais antigos, apesar de toda variedade, apresentam uma imagem relativamente uniforme: eles retratam os judeus como um povo de 'filósofos'". Cf. Ginsburg (1934, p. 120), Momigliano (1975a, p. 8486). Esta perspectiva chegou a ser apropriada pelos próprios judeus, tanto na apresentação do judaísmo por Filo de Alexandria como um sistema filosófico, ou ainda na concepção de 4 Macabeus $(7,7)$, que apresenta Eleazar como "o filósofo com a vida divina" (

${ }^{31}$ Como bem indicou Fergus Millar (2006, p. 73), pode-se perceber na Antiguidade o "crescimento de uma concepção de um único deus supremo, referenciado em vários nomes". A este respeito, cf. Teixidor (1977). Pode bem ser que a religião judaica, com sua proposta monoteísta, tenha influenciado em certa medida na formação desta concepção, juntamente com outras influências paralelas, como a filosofia estoica. Isto não significa que os estoicos, como Sêneca, tivessem uma perspectiva monoteísta, mas antes que concebiam deus como "uma divindade que é, a princípio, unitária e sem qualquer tipo de aparência ou vontade semelhante à humana" (COSTA JUNIOR; FRIGHETTO, 2016, p. 54). Segundo Sérvio, comentando a Eneida, "é claro para os estoicos que deus é um, cujos nomes variam de acordo com os seus atos e funções" (et sciendum Stoicos dicere unum esse deum, cui nomina variantur pro actibus et officiis, cf. Sérvio, Ad Aeneidem, 4, 638). Um exemplo de correlação entre a perspectiva estoica e a judaica se dá na apresentação de Estrabão da religião judaica (Geographica, 16, 2, 35), a qual é concebida aos moldes da filosofia estoica. Cf. Ludlam (2010, p. 525). ${ }^{32}$ A negatividade da reação sobre a cultura judaica não elimina sua importância, até porque, como bem destacou
} 
A relação entre helenismo e judaísmo, portanto, como se pode perceber no estudo do livro de 2 Macabeus - mesmo que este defenda opinião diferente - foi muito mais um exemplo de fusão e difusão cultural - característico do mundo helenístico,$-^{33}$ do que propriamente um conflito rígido entre duas culturas ${ }^{34}$. Trata-se de interação, e não imposição. Ao invés de se pensar na "helenização" da Judeia, ${ }^{35}$ ou mesmo na "asiatização" da Grécia, ${ }^{36}$ se deve ter em mente uma interação cultural de mão dupla, cuja intensidade e profundidade é dificilmente medida, uma vez que não se trata da adaptação de elementos culturais externos, mas da transformação interna de cada cultura em suas várias dimensões (econômica, social, artística, ${ }^{37}$ literária, etc).

Afinal, culturas não são estáticas e sólidas, ${ }^{38}$ mas antes possuem qualidade relacional, definindo suas identidades justamente quando estão em contato com o que Ihe é diferente e estranho, mesmo - ou talvez, principalmente - quando se estabelece uma situação de conflito. Ideologicamente, portanto, a oposição existiu, de modo a não somente delinear a história subsequente dos judeus, mas também definir o próprio judaísmo. Lembramos aqui da já antes citada afirmação de Gideon Bohak (2000a, p. 351) de que "muito da história da civilização judaica no mundo Greco-Romano pode ser vista como uma luta para definir como exatamente os judeus deveriam se relacionar com esta cultura estrangeira". Acontece, porém, que esta "história" pode ser compreendida não somente em termos historiográficos - como leitura sobre o passado $-{ }^{39}$ mas também como realidade histórica: ${ }^{40}$ os acontecimentos subsequentes de fato foram influenciados

Yehoshua Amir, no que diz respeito às relações entre as culturas grega e judaica, seja em aspecto positivo ou negativo, estas "não falharam em deixar seus efeitos nas culturas do mundo todo" (AMIR, 1975, p. 67).

${ }^{33}$ Cf. Hadas (1959).

${ }^{34} \mathrm{~A}$ posterior presença de elementos de ambas culturas na tradição cristã indica, segundo Eric M. Meyers, que a relação entre as culturas grega e judaica "não precisa ser vista tanto como um conflito entre duas culturas, mas antes como o encontro de duas tradições" (MEYERS, 1992, p. 91).

${ }^{35}$ Cf. p.e. Hengel (1989).

${ }^{36}$ Como bem lembram Biazotto e Funari (2015, p. 246, nota 2), o historiador inglês George Grote defendeu que a intenção de Alexandre o Grande seria justamente "asiatizar" a Grécia e a Macedônia. Apesar desta percepção tirar a usual ênfase na influência grega sobre as demais culturas, mantém o problema de apresentar o processo como unilateral - afinal, apenas inverte a direção do mesmo.

${ }^{37} \mathrm{O}$ primeiro grande nome a não somente indicar que a influência grega pode ser percebida na arte judaica, mas também estudar a mesma com profundidade, foi Erwin Ramsdell Goodenough (1893-1965), que além de uma gigantesca obra sobre os símbolos judaicos no período helenístico (para a versão compilada, GOODENOUGH, 1988) também buscou apresentar os resultados de sua pesquisa sobre a compreensão da helenização do judaísmo. Cf. p.e.: Goodenough (1937). ${ }^{38}$ Como lembram Eugene Coetzer e Pierre Jordaan (2009, p. 190), o judaísmo "não deve ser visto como um conceito que foi moldado em uma ideia estática. É pelo contrário uma fonte de vida para a identidade política e religiosa do povo judeu". Sendo assim, o "judaísmo é uma força sempre mutante que levou uma nação a sobreviver por mais de três milênios e meio".

${ }^{39}$ Que é o sentido utilizado na análise do segundo capítulo.

40 Uma vez que o evento histórico, definido por Michael Oakeshott (2003, p. 120) como eventus, tem como caráter histórico "a diferença que ele fez em uma passagem de eventos históricos circunstancial e significativamente relacionados", pode-se pensar na própria leitura de 2 Macabeus da Revolta dos Macabeus não somente como história em sentido historiográfico, mas também em sentido eventual (realidade histórica), uma vez que se apresenta como um 
pela variante relação com a cultura grega, como se pode perceber no conflito entre os diversos grupos religiosos judaicos. Fariseus, saduceus, essênios, zelotes e herodianos - cada um destes grupos possuiu uma relação específica com a cultura estrangeira e mesmo com o poder estrangeiro no território judeu. ${ }^{41}$

\section{A influência da "invenção do bárbaro" na invenção do judaísmo}

Historicamente, a relação entre gregos e judeus apresentada por 2 Macabeus possui muitas semelhanças com a anterior relação entre gregos e persas, de modo que fica evidente que da mesma forma que as Guerras Médicas foram fundamentais não somente na "invenção do bárbaro" mas também na construção de uma identidade grega, ${ }^{42}$ a Revolta dos Macabeus se constituiu em um evento fundamental não somente na criação da ideia de "helenização" como também na própria construção da identidade judaica.

Como bem identificado por Tessa Rajak (2001, p. 7), a "oposição simbólica ao helenismo, associada à lembrança do tempo de crise, foi uma parte óbvia no caminho no qual os judeus da Palestina construíram sua própria identidade", uma vez que foi "importante e por fim até criativo ver os gregos como diferentes deles em aspectos particulares". Deste modo, pode-se pensar que a função de 2 Macabeus na constituição da identidade judaica foi em grande medida semelhante à função da literatura trágica na definição da identidade grega: ${ }^{43}$ forneceu a relação de oposição necessária - mesmo

evento (mesmo que processual) que se relaciona e influencia eventos subsequentes, a partir de uma relação específica com eventos precedentes.

${ }^{41}$ A respeito dos grupos religiosos judaicos mencionados, cf. p.e., Schubert (1979) e Scardelai (2008, p. 107-128). De fato, "as incursões do helenismo geraram uma atitude mais séria e mais estrita entre os seguimentos da população judaica", como lembra Meyers (1992, p. 86), de modo que "foi esse contexto de confluência de culturas que fizera emergir grupos divergentes no complexo universo judaico", como indica Donizete Scardelai (2008, p. 111). Os grupos judaicos, portanto, "foram o resultado desse encontro cultural, rejeitado por uns, mas ajustado por outros".

${ }^{42}$ Cf. Hall (1989, p. 57-62) e Mitchell (2013, p. 2990-2992). Segundo Paul Cartledge (2007, p. 308), a conquista da Grécia pelo Império Persa colaborou na ampliação do significado do termo $\beta \alpha ́ \rho \beta \alpha \rho \circ \varsigma$, que de uma diferença cultural, passou

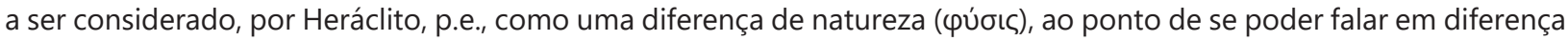

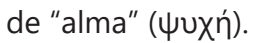

${ }^{43}$ Sobre a importância da tragédia na constituição da identidade grega, cf. Hall (1989). A respeito desta questão na obra Suplicantes de Ésquilo, cf. Mitchell (2006); na obra Os Persas de Ésquilo, cf. Goldhill (2002); nas tragédias de Eurípides, cf. Saïd (2002). Segundo François Hartog (1999, p. 326), "a afirmação de uns como gregos está ligada à constituição de outros como bárbaros", de modo que se pode pensar que em Homero "não há bárbaros" e, consequentemente, "não há também gregos". O próprio conceito de "E $\lambda \lambda \eta v \varepsilon \varsigma$, portanto, se constrói em oposição aos bárbaros. Cf. Windisch (1985, p. 504-516 (II)). 
que muito mais imaginária que real ${ }^{44}$ - para a consolidação de uma identidade cultural. ${ }^{45}$

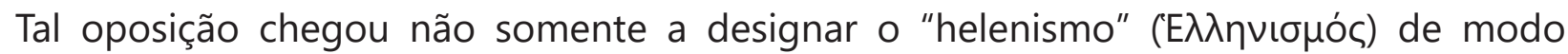

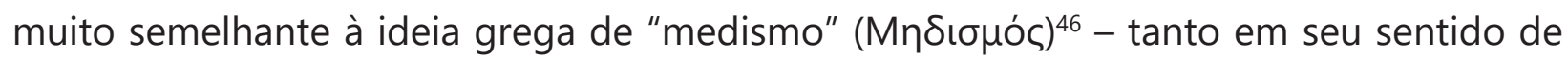
assimilação cultural como de traição política -, mas também culminou na criação do

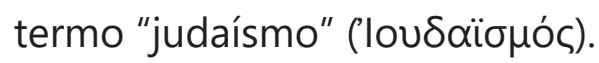

Este novo termo surge fundamentado em uma concepção de sacralidade territorial

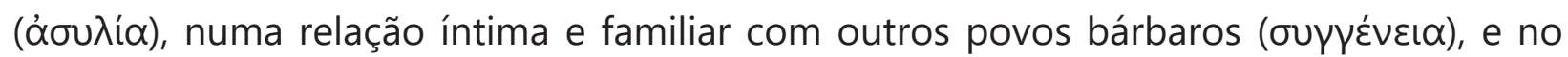

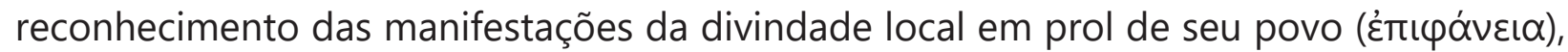
ou seja, a partir de fenômenos próprios do mundo helenístico, ${ }^{47}$ demonstrando que 0 próprio conceito de judaísmo, portanto, mesmo sendo formado a partir de uma oposição ao helenismo, foi propriamente uma invenção helenística.

\section{O que significa uma "invenção helenística"?}

Afirmar que a ideia de judaísmo foi "uma invenção helenística" não significa que o judaísmo tenha sido criado a partir da cultura grega, como parece sugerir Shaye Cohen (1999), ou que os judeus aprenderam a serem judeus com os gregos, como critica Steven Weitzman (2017, p. 207 e ss). Afinal, afirmar estas coisas seria negar a originalidade dos judeus na apropriação da cultura helenística, seguindo uma ideia de "helenização" como imposição externa e não como fusão e difusão, tal como sugerimos na introdução deste trabalho. Sendo assim, afirmar que o judaísmo é uma invenção helenística significa vê-los como uma construção judaica dentro de um contexto e a partir de elementos próprios do período helenístico, no qual os judeus não eram meros receptores passivos, mas um povo ativo e criativo que utilizou o contexto cultural da época como ferramenta para delinear sua própria identidade.

\footnotetext{
44 Segundo Suzanne Saïd (2002, p. 99), assim como se pode definir a geração das Guerras Persas (Médicas) como aquela que "realmente elaborou a antítese grego/bárbaro", se pode perceber na obra Os Persas de Ésquilo "a mais perfeita defesa e ilustração desta visão de mundo bipolar". Os Persas, portanto, apresenta uma visão um tanto quanto exagerada e imaginária, principalmente quando comparada à obra Orestes de Eurípides, na qual se abre a possibilidade de transposição: gregos podem se tornar bárbaros ( $\beta \alpha \rho \beta \alpha \rho o ́ \omega$, cf. Eurípides, Orestes, 485), por exemplo. Cf. Saïd (2002, p. 100). Não é de se surpreender, portanto, com a possibilidade de influência direta de Os Persas em 2 Macabeus, tal como a semelhança entre duas passagens (Ésquilo, Persae, 744-751; 2 Mac. 9, 8-12), bem destacada por Daniel R. Schwartz (1998, p. 227), parece fundamentar.

${ }^{45}$ Considerando-se o conceito de imaginário social, não somente se pode estabelecer uma consciência sobre o potencial transformativo da interculturalidade, como ainda que os imaginários sociais de um dado grupo moldam as "ideias e práticas dos seus membros e são consequentemente permanentemente sujeitas a transformações em resposta a contatos com o mundo exterior" (STAVRIANOPOULOU, 2013, p. 199).

${ }^{46}$ Sobre o "medismo", cf. Graf (1984).

${ }^{47}$ Como bem lembra I. Stavrianopoulou (2013, p. 180), nenhum destes três fenômenos surgiu no período helenístico, uma vez que já existiam no período clássico, porém todos estes ganham destaque, aumentam em número e se apresentam especialmente nas cidades subjugadas pelos Impérios helenísticos.
} 
Por fim, cabe destacar que dizer "invenção" não implica em falsidade ou mesmo completa artificialidade: não é porque a base sobre o qual o judaísmo se estabeleceu - a oposição com o helenismo - foi artificial que o judaísmo também será: afinal, mesmo que tenha surgido a partir desta construção ideológica, a identidade judaica passa a ser uma realidade interior, que "tem como fundamento um sentimento pessoal, emocional e intelectual do que é ser judeu" (SORJ, 2008, p. 323), ultrapassando a ideologia inicial.

A conclusão a que chegamos, portanto, não significa que a atual ideia de judaísmo seja um engano nas mentes e corações de quem se identifica por esta cultura, como alguns sugerem quando indicam a historicidade da identidade judaica. Antes, significa que o judaísmo, assim como toda e qualquer identidade cultural, necessitou de uma oposição para estabelecer seus fundamentos, definir suas características e consolidar sua identidade, que certamente mudou e ainda tem mudado consideravelmente desde então. Afinal, seja a nível individual ou coletivo, somente tomamos consciência do "eu" no contato com o "tu", ${ }^{48}$ com o outro. Somente com a alteridade há de fato identidade, e esta é a grande lição da história de formação do conceito de judaísmo, uma verdadeira invenção helenística.

\section{Referências}

\section{Documentação textual}

AESCHYLUS. Persians; Seven against Thebes; Suppliants; Prometheus bound. Edited and translated by Alan H. Sommerstein. Revised edition. Cambridge: Harvard University Press, 2009.

BÍBLIA DE JERUSALÉM. Tradução de Gilberto da Silva Gorgulho, Ivo Storniolo e Ana Flora Anderson. São Paulo: Paulus, 2013.

EURIPIDES. In four volumes. With an English translation by Arthur S. Way. London: William Heinemann, 1929. v. II.

EUSEBIUS. The proof of the gospel being the Demonstratio Evangelica of Eusebius of Ccesarea. Translated by W. J. Ferrar. London: The Macmillan Company, 1920. v. I.

JOSEPHUS. The Jewish War (books IV-VII). With an English translation by H. St. J. Thackeray. London: William Heinemann, 1961. v. III.

SEPTUAGINTA. Editio Alfred Rahlfs et Robert Hanhart. Stuttgart: Deutsche Bibelgesellschaft, 2011.

\footnotetext{
${ }^{48}$ Sobre esta necessidade do "tu" na construção do "eu", cf. Buber (2003).
} 
SERVIUS. Servius' Commentary on book four of Virgil's Aeneid. Translation by Christopher M. McDonough, Richard E. Prior and Mark Stansbury. Wauconda: Bolchazy-Carducci Publishers, 2004.

STRABO. The Geography. With an English translation by Horace Leonard Jones. London: William Heinemann, 1930. v. VII.

TERTULLIAN. Adversus Marcionem. Edited and Translated by Ernest Evans. Oxford: Oxford Clarendon Press, 1972. v. II

THE APOSTOLIC FATHERS. Edited and translated by Bart D. Ehrman. Cambridge: Harvard University Press, 2003. v. I.

\section{Obras de apoio}

AMIR, Y. The reaction of the Hellenistic world to Judaism. Immanuel, v. 5, p. 67-73, 1975.

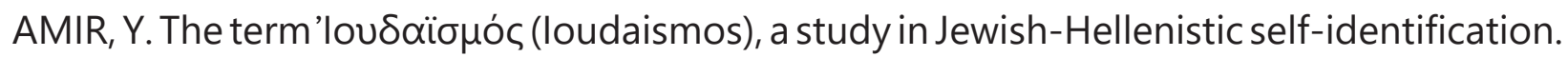
Immanuel, v. 14, p. 34-41, 1982.

BAUMAN, Z. Identidade. Rio de Janeiro: Jorge Zahar, 2005.

BIAZOTTO, T. do A.; FUNARI, P. P. A. A sabedoria bárbara e os limites da helenização: o mundo helenístico de Arnaldo Momigliano. História da Historiografia, n. 17, p. 244261, 2015.

BOHAK, G. Hellenism. In: SCHIFFMAN, L. H.; VANDERKAM, J. C. (Ed.). Encyclopedia of the Dead Sea Scrolls. Oxford: Oxford University Press, 2000, p. 350-352.

BOHAK, G. The impact of Jewish monotheism on the Greco-Roman world. Jewish Studies Quarterly, v. 7, p. 1-21, 2000.

BOYARIN, D. Border lines: the partition of Judaeo-Christianity. Philadelphia: University of Pennsylvania Press, 2004.

BUBER, M. Eu e Tu. São Paulo: Centauro, 2003.

CARTLEDGE, P. Greeks and "barbarians", In: CHRISTIDIS, A.-F. (Ed.). A History of Ancient Greek: from the beginnings to Late Antiquity. Cambridge: Cambridge University Press, 2007, p. 307-313.

CHEVITARESE, A. L.; CORNELLI, G. Judaísmo, cristianismo, helenismo: ensaios sobre interações culturais no Mediterrâneo Antigo. Itu: Ottoni, 2003.

COETZER, E.; JORDAAN, P. J. Selling religious progress to a nostalgic nation: Jewish doctrinal revolution in 2 Maccabees 7. Ekklesiastikos Pharos, v. 91, n. 20, p. 179190, 2009.

COHEN, S. J. D. Judaism without circumcision and "Judaism" without "circumcision" in Ignatius. Harvard Theological Review, v. 95, n. 4, p. 395-415, 2002. 
COHEN, S. J. D. The beginnings of Jewishness: boundaries, varieties, uncertainties. Berkeley: University of California Press, 1999.

COLLINS, J. J. Jewish cult and Hellenistic culture: essays on the Jewish encounter with Hellenism and Roman rule. Leiden: Brill, 2005.

COSTA JUNIOR, C. L. J. da; FRIGHETTO, R. A concepção de deus no De Providentia de Sêneca. Hélade, v. 2, n. 3, p. 51-58, 2016.

DEGAN, A. A identidade incômoda: uma proposta de leitura do Bellum Judaicum de Flávio Josefo. Politeia, v. 9, n. 1, p. 213-237, 2009.

DILLERY, J. The first Egyptian narrative history: Manetho and Greek Historiography. Zeitschrift für Papyrologie und Epigraphik, n. 127, p. 93-116, 1999.

ELIAS, N. Introdução à Sociologia. Lisboa: Edições 70, 2005.

FELDMAN, L. H. How much hellenism in Jewish Palestine? Hebrew Union College Annual, v. 57, p. $83-111,1986$.

FERNANDÉZ MARCOS, N. La religión judia vista por los autores griegos y latinos. Sefarad, v. 41, n. 1, p. 3-25, 1981.

GINSBURG, M. S. Sparta and Judaea. Classical Philology, v. 29, n. 2, p. 117-120, 1934.

GMIRKIN, R. E. Berossus and Genesis, Manetho and Exodus: Hellenistic histories and the date of the Pentateuch. New York/London: T\&T Clark, 2006.

GOLDHILL, S. Battle narrative and politics in Aeschylus' Persae. In: HARRISON, T. (Ed.). Greeks and Barbarians. New York: Routledge, 2002, p. 50-61.

GOODENOUGH, E. R. Jewish symbols in the Graeco-Roman period. Princeton: Princeton University Press, 1988.

GOODENOUGH, E. R. New light on Hellenistic Judaism. Journal of Bible and Religion, v. 5, n. 1, p. 18-28, 1937.

GRABBE, L. L. The Jews and Hellenization: Hengel and his critics. In: DAVIES, P. R.; HALLIGAN, J. M. (Ed.). Second Temple Studies III: studies in politics, class and material culture. Sheffield: Sheffield Academic Press, 2002, p. 52-66.

GRAF, D. F. Medism: the origin and significance of the term. Journal of Hellenic Studies, v. 104 , p. 15-30, 1984.

GRUEN, E. S. Jews and Greeks. In: ERSKINE, A. (Ed.). A Companion to the Hellenistic World. Oxford: Blackwell, 2005, p. 264-279.

HABICHT, Ch. The Hellenistic Monarchies: selected papers. Ann Arbor: The University of Michigan Press, 2006.

HADAS, M. Hellenistic culture: fusion and diffusion. New York: Columbia University Press, 1959. 
HALL, E. Inventing the Barbarian: Greek self-definition through tragedy. Oxford: Clarendon Press, 1989.

HALL, S. Identidade cultural e diáspora. Revista do Patrimônio Histórico e Artístico Nacional, n. 24, p. 68-75, 1996.

HARTOG, F. O espelho de Heródoto: ensaio sobre a representação do outro. Belo Horizonte: UFMG, 1999.

HENGEL, M. Judaism and Hellenism: studies in their encounter in Palestine during the Early Hellenistic Period. Philadelphia: Fortress Press, 1974. 2 v.

HENGEL, M. The 'Hellenization' of Judaea in the first century after Christ. London: SCM Press; Trinity Press International, 1989.

HIDALGO DE LA VEGA, Ma. J. Algunas reflexiones sobre los límites del oikoumene en el Imperio Romano. Gérion, v. 23, n. 1, p. 271-285, 2005.

HIDALGO DE LA VEGA, M. J. Identidad griega y poder romano en el Alto Imperio: frontera en los espacios culturales y ideologicos. In: LÓPEZ BARJA, P.; REBOREDA MORILLO, S. (Ed.). Fronteras e identidad en el Mundo Griego Antiguo. Santiago de Compostela: Universidade de Santiago de Compostela, 2001, p. 139-156.

HIDALGO DE LA VEGA, M. J. Roma protectora del helenismo: el poder de la identidad. In: PLÁCIDO SUÁREZ, Domingo et al. (Ed.). La construcción ideológica de la ciudadanía: identidades culturales y sociedad en el mundo griego antiguo. Madrid: Universidad Complutense, 2006, p. 423-448.

HIMMELFARB, M. Judaism and Hellenism in 2 Maccabees. Poetics Today, v. 19, n. 1, p. 1940, 1998.

JAEGER, W. Cristianismo primitivo e paideia grega. Lisboa: Edições 70, 2002.

JOHNSON, A. P. Ethnicity and argument in Eusebius' Praeparatio Evangelica. Oxford: Oxford University Press, 2006.

JOHNSON, S. R. Historical fictions and Hellenistic Jewish identities: Third Maccabees in its cultural context. Berkeley: University of California Press, 2005.

KELLNER, D. A cultura da mídia. Bauru: Edusc, 2001.

KOSMIN, P. J. Indigenous revolts in 2 Maccabees: the Persian version. Classical Philology, v. 111, p. 32-53, 2016.

KUHRT, A. Berossus' Babyloniaka and Seleucid rule in Babylonia. In: KUHRT, A.; SHERWINWHITE, S. (Ed.). Hellenism in the East: the interaction of Greek and non-Greek civilizations from Syria to Central Asia after Alexander. Berkeley: University of California Press, 1987, p. 32-56. 
LUDLAM, I. Appendix: the God of Moses in Strabo. In: BAR-KOCHVA, B. The image of the Jews in Greek literature: the Hellenistic period. Berkeley: University of California Press, 2010, p. 525-541.

MAIRS, R. Hellenization. In: BAGNALL, R. S. et al. (Ed.). The Encyclopedia of Ancient History. New York: Blackwell, 2013, p. 3122-3125.

MASON, S. Jews, Judaeans, Judaizing, Judaism: problems of categorization in Ancient History. Journal for the Study of Judaism, v. 38, p. 457-512, 2007.

MEYERS, E. M. The challenge of Hellenism for early Judaism and Christianity. Biblical Archaeologist, v. 55, n. 2, p. 84-91, 1992.

MILLAR, F. The background to the Maccabean revolution: reflections on Martin Hengel's "Judaism and Hellenism". In: MILLAR, F. Rome, the Greek World, and the East. Chapel Hill: The University of North Carolina Press, 2006b, p. 67-90. 3 v.

MITCHELL, L. G. Greeks, Barbarians, and Aeschylus' suppliants. Greece \& Rome, v. 53, n. 2, p. 205-223, 2006.

MITCHELL, L. G. Greekness. In: BAGNALL, R. S. et al. (Ed.). The Encyclopedia of Ancient History. New York: Blackwell, 2013, p. 2990-2992.

MOMIGLIANO, A. Alien wisdom: the limits of Hellenization. Cambridge: Cambridge University Press, 1975a.

MOMIGLIANO, A. As raízes clássicas da historiografia moderna. Bauru: EDUSC, 2004.

MOMIGLIANO, A. The date of the first book of the Maccabees. In: L'ttalie préromaine et la Rome républicaine: mélanges offerts à Jacques Heurgon. Rome: École Française de Rome, 1976, p. 657-661.

MOMIGLIANO, A. The second book of the Maccabees. Classical Philology, v. LXX, n. 2, p. 81-88, 1975b.

NOVENSON, M. V. Paul's former occupation in ioudaismos. In: ELLIOTT, M. W.; HAFEMANN, S. J.; WRIGHT, N. T.; FREDERICK, J. (Ed.). Galatians and Christian theology: justification, the gospel, and ethics in Paul's Letter. Grand Rapids: Baker Academy, 2014, p. 2439.

OAKESHOTT, M. Sobre a história e outros ensaios. Rio de Janeiro: Topbooks, 2003.

OLIVEIRA, R. C. Identidade, etnia e estrutura social. São Paulo: Pioneira, 1976.

RAJAK, T. The Jewish dialogue with Greece and Rome: studies in cultural and social interaction. Leiden: Brill, 2001.

RUPPENTHAL NETO, W.; FRIGHETTO, R. Um símbolo da diferença: pertença, violência e resistência na circuncisão judaica. Estudos Teológicos, v. 57, n. 2, p. 426-443, 2018.

RUPPENTHAL NETO, W. Introdução à teologia de 1 Macabeus. Teologia e Espiritualidade, v. 4, n. 7, p. 71-90, 2017. 
RUPPENTHAL NETO, W. Martírio e resistência em 2 Macabeus. Estudos de Religião, v. 33, n. 1, p. 231-252, 2019.

SAÏD, S. Greeks and Barbarians in Euripides' Tragedies: the end of difference? In: HARRISON, T. (Ed.). Greeks and Barbarians. New York: Routledge, 2002, p. 62-100.

SCARDELAI, D. Da religião bíblica ao judaísmo rabínico: origens da religião de Israel e seus desdobramentos na história do povo judeu. São Paulo: Paulus, 2008.

SCHUBERT, K. Os partidos religiosos hebraicos da época neotestamentária. São Paulo: Paulinas, 1979.

SCHWARTZ, D. R. On something biblical about 2 Maccabees. In: STONE, M. E.; CHAZON, E. G. (Ed.). Biblical perspectives: early use and interpretation of the Bible in light of the Dead Sea Scrolls. Leiden: Brill, 1998, p. 223-232.

SILVA, G. V. A condenação dos judaizantes nos Concílios Eclesiásticos do século IV. Phoînix, V. 14, p. 164-188, 2008.

SILVA, T. T. A produção social da identidade e da diferença. In: (Org.). Identidade e diferença: a perspectiva dos Estudos Culturais. Petrópolis: Vozes, 2000, p. 73-102.

SMITH, M. Palestinian parties and politics that shaped the Old Testament. New York: Columbia University Press, 1971.

SOARES, D. O. As influências persas no chamado judaísmo pós-exílico. Revista Theos, v. 5, n. 2, p. 1-24, 2009.

SORJ, B. Identidade judaica, diversidade e unidade. In: FUKS, S. (Coord.). Tribunal da História, volume II: processos de formação da identidade judaica e do anti-semitismo. Rio de Janeiro: Centro de História e Cultura Judaica, 2008, p. 323-339.

STAVRIANOPOULOU, E. Hellenistic world(s) and the elusive concept of "Greekness". In: (Ed.). Shifting social imaginaries in the Hellenistic period: narrations, practices, and images. Leiden: Brill, 2013, p. 177-205.

TEIXIDOR, J. The pagan God: popular religion in the Greco-Roman Near East. Princeton: Princeton University Press, 1977.

TODOROV, T. O medo dos bárbaros: para além do choque das civilizações. Petrópolis: Vozes, 2010.

VEYNE, P. Introdução. In: (Org.). História da vida privada: do Império Romano ao Ano Mil. São Paulo: Companhia das Letras, 1993, p. 13-15.

WEITZMAN, S. The origin of the Jews: the quest for roots in a rootless age. Princeton: Princeton University Press, 2017.

WILKER, J. "God is with Italy now": pro-roman Jews and the Jewish Revolt. In: ECKHARDT, B. (Ed.). Jewish identity and politics between the Maccabees and Bar Kokhba: groups, normativity, and rituals. Leiden: Brill, 2012, p. 157-187. 
WILLIAMS, R. Cultura. Rio de Janeiro: Paz e Terra, 1992.

WINDISCH, H. "E $\mathrm{X} \lambda \eta \eta$, etc. In: KITTEL, G.; FRIEDRICH, G. (Ed.). Theological dictionary of the New Testament. Grand Rapids: Eerdmans, 1985, p. 504-516.

WOODWARD, K. Identidade e diferença: uma introdução teórica e conceitual. In: SILVA, T. T. da. (Org.). Identidade e diferença: a perspectiva dos Estudos Culturais. Petrópolis: Vozes, 2000, p. 7-72.

WOOLF, G. Becoming Roman, staying Greek: culture, identity, and the civilizing process in the Roman East. Proceedings of the Cambridge Philological Society, v. 40, p. 116143, 1994. 